\title{
Vancomycin in infusion during vitrectomy in surgical treatment of acute postoperative and posttraumatic endophthalmitis
}

Robert Rejdak ${ }^{1,2}$, Tomasz Choragiewicz ${ }^{1,3}$, Agnieszka Kalinowska ${ }^{1}$, Michael J. Koss ${ }^{4}$, Piotr Ksiazek ${ }^{5}$, Joanna Moneta-Wielgos ${ }^{1}$, Ryszard Maciejewski ${ }^{6}$, Anselm G. Jünemann ${ }^{7}$ and Katarzyna Nowomiejska ${ }^{1 *}$

\begin{abstract}
Background: Endophthalmitis is potentially devastating intraocular inflammation following eye trauma or surgery. We describe the visual outcomes and causative pathogens in acute bacterial postoperative and posttraumatic endophthalmitis treated with immediate pars plana vitrectomy (PPV) with Vancomycin dissolved in the infusion fluid.

Methods: Clinical records of consecutive 30 patients with postoperative endophthalmitis and 15 patients with posttraumatic endophthalmitis were evaluated. Vancomycin was administered constantly in the infusion fluid at the time of complete PPV. Cultures were prepared from anterior chamber paracentesis. The mean follow-up period was 13 months.

Results: The visual acuities were improved in 38 cases (84\%) and remained stable in seven cases (16\%). Median post-PPV visual acuity was $1.0 \log$ MAR in a group with postoperative endophthalmitis and $1.3 \log$ MAR in a group with posttraumatic endophthalmitis $(p<0.05)$. Twenty cases $(44 \%)$ were culture-positive (Staphylococcus, Streptococcus, Enterococcus and Bacillus spp).
\end{abstract}

Conclusions: Early PPV with Vanomycin in infusion leads to vision improvement in patients with both posttraumatic and postoperative endophthalmitis. In our series of 45 cases culture was positive only in half of the cases.

Keywords: Endophthalmitis, Ocular trauma, Vitrectomy

\section{Background}

Endophthalmitis is a severe and potentially devastating intraocular purulent inflammation resulting from infectious agent invasion to the posterior segment of the eye occurring as a complication of an operation procedure, penetrating eye injuries or hematogenous spread of bacteria [1]. Endophthalmitis may lead to loss of vision due to irreversible damage of photoreceptors caused by bacterial toxins.

Approximately $70 \%$ of cases occur as a complication of the intraocular surgery, mostly cataract extraction.

\footnotetext{
* Correspondence: katarzynanowomiejska@mailcity.com

${ }^{1}$ Department of General Ophthalmology, Medical University of Lublin, ul.

Chmielna 1, 20-079 Lublin, Poland

Full list of author information is available at the end of the article
}

Capsular or zonular surgical complication and wound leak on the next day after surgery are the main risk factors for the postoperative endophthalmitis [2]. Posttraumatic endophthalmitis following open-globe injuries accounts for one-fourth of all cases of endophthalmitis [3] and may have a significant impact on socioeconomic life. The likelihood of infection after penetrating ocular trauma (3.3 to $17 \%$ ) is 100 times greater than after cataract surgery (0.05\%) [4]. Rural setting [5], delayed wound closure [6] and dirty wound [7] are the main risk factors for endophthalmitis after penetrating eye trauma. Other risk factors are: retained intraocular foreign body (IOFB) [6] and ruptured lens capsule [4].

The treatment of endophthalmitis has evolved during the last several decades. Before the age of vitreoretinal 
surgery, enucleation of affected eye was usually performed [8]. In the 1970s treatment of endophthalmitis greatly improved by introduction of intravitreal antibiotics. Intravitreal injection of empirical choice antibiotic (1 mg Vancomycin or $2.25 \mathrm{mg}$ Ceftizidime) is still used in many countries in the primary treatment of endophthalmitis and is called the "silver standard" by European Society of Cataract and Refractive Surgeons (ESCRS) guidelines [2]. Since 1980, the success rate of surgical treatment-pars plana vitrectomy (PPV)-defined as final vision of 20/400 or better-has increasingly improved, ranging from 42 to $73 \%$. Therefore, complete PPV is now considered the "gold standard" in the treatment of endophthalmitis [2].

Vancomycin is considered to be the drug of choice for empiric coverage of Gram-positive organisms - the most common cause both in posttraumatic and postoperative endophthalmitis. Vancomycin is widely used in the treatment of endophthalmitis as intravitreal injection alone or at the end of PPV using the 25G or $30 \mathrm{G}$ needle [2].

The objective of this study was to characterize the visual outcome and causative pathogens in patients with postoperative and posttraumatic endophthalmitis who had been treated with immediate PPV with Vancomycin dissolved in infusion.

\section{Methods}

In this noncomparative case series we have analyzed retrospectively medical records of consecutive 45 patients with acute endophthalmitis - 15 posttraumatic and 30 acute postoperative bacterial endophthalmitis treated at the Department of General Ophthalmology in Lublin, Poland, between 2010 and 2015. This study followed the tenets of the Declaration of Helsinki. The treatment chosen in the study was a part of a standard care. The study was approved by the local Ethic Committee at the University in Lublin, Poland. The patients gave their written informed consent to participate in the study and publish the data.

Inclusion criteria were as follows: (1) clinical signs of endophthalmitis: lid edema, chemosis, conjunctival hyperaemia, anterior chamber and vitreous cells, hypopyon, corneal edema, corneal ring infiltrate, reduced red reflex and afferent pupillary defect; (2) eye trauma or intraocular surgery performed less than 6 weeks ago; (3) PPV with Vancomycin in tapping performed within $6 \mathrm{~h}$ from the beginning of signs of endophthalmitis.

The diagnosis of endophthalmitis was made on the basis of clinical examination and ultrasonography. The patient data were recorded including: age, gender, type of trauma, previous surgical procedures, primary and final visual acuity, result of microbiological examination. Functional (best-corrected visual acuity: improved, stable, worsened) and anatomic outcomes (retinal attachment, intraocular pressure) were assessed during the follow-up.

Snellen decimal best corrected visual acuity was recorded in the affected eyes and converted into logarithm of the minimum angle of resolution (logMAR). Initial and the final best-corrected visual acuities were compared.

There were 13 men and two women in posttraumatic group and 14 men and 16 women in postoperative group. Overall, the median age of patients was 60 years (range 20-80 years), 40 years in posttraumatic patients and 70 years in postoperative patients $(p<0.0001)$.

Previous surgical procedures included: 20 phacoemulsyfications with IOL implantation, three bevacizumab injections, three secondary IOL implantations, one trabeculectomy, one Ahmed valve implantation, one PPV, one extracapsular cataract extraction.

Most of the surgeries included cataract surgery. As all cataract surgeries were performed in another hospitals, we do not have a knowledge what was the incision length, if preoperative fluorochinolones and intracameral cefuroxime was used as a prophylaxis of endophthalmitis.

Ocular trauma data included the mechanism and type of injury classified according to the Ocular Trauma Classification. Zone I injuries are confined to the cornea, zone II injuries involve the anterior $5 \mathrm{~mm}$ of the sclera, and zone III injuries involved full-thickness scleral defects more posterior than $5 \mathrm{~mm}$ from the limbus [9]. Wound location in posttraumatic eyes was classified as zone I in seven eyes, as zone II in three eyes and as zone III in three eyes.

The preoperative examination included visual acuity, intraocular pressure and B-scan ultrasonography. The follow-up examination included: visual acuity, intraocular pressure, and retinal attachment assessed with fundus examination after dilatation. The mean follow-up period was 13 months (range 10-20 months). Patients were examined on the next day after 1 week, after 1 month, 3 months, 6 months and year after operation.

Statistical computations were performed using GraphPad InStat software.

\section{Surgical procedure}

At the day of admission (within $6 \mathrm{~h}$ ) a standard threeport immediate and complete 23G PPV (Constellation, Alcon, US) was performed under general or peribulbar anesthesia. In posttraumatic cases the corneal or scleral laceration was sutured, if it was not done in the region hospital.

Microbiological cultures were prepared from anterior chamber via paracentesis (Fig. 1) or using the vitrectomy cutter before switching on the irrigation. To obtain anterior-chamber samples $27 \mathrm{G}$ needle was inserted into the anterior chamber via limbus and $0.1 \mathrm{~mL}$ of fluid was aspirated to the tuberculin syringe. On the initiation of 


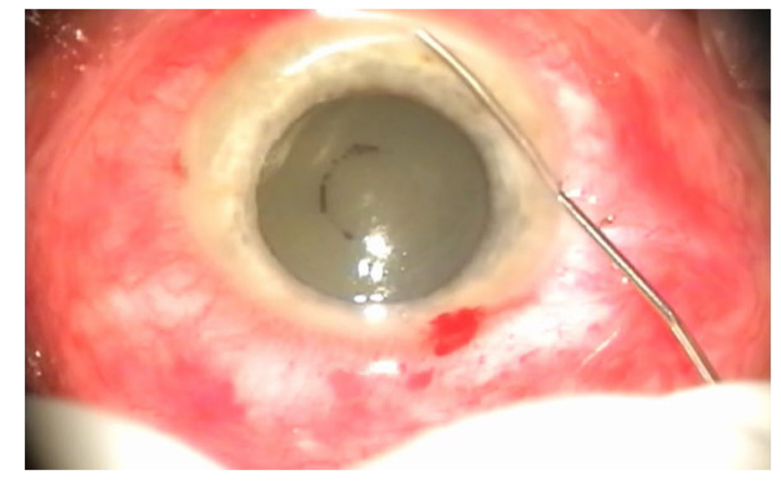

Fig. 1 Aspiration of the hypopyon for microbiological culture

the PPV $0.2 \mathrm{~mL}$ of undiluted vitreous was aspirated into a syringe connected to the infusion line.

After phacoemulsification with intraocular lens (IOL) implantation in phakic eyes was done, the anterior chamber maintainer was installed (Fig. 2) if there were difficulties with visualization of the infusion line into vitreous cavity. Next, the induction of posterior vitreous detachment (Fig. 3) as well as periphery shaving (Fig. 4) was performed. Intraocular Vancomycin $(0.2 \mathrm{mg} / \mathrm{ml})$ was administered at the time of PPV in the balanced salt solution (BSS) Plus (Alcon, Forth Worth, Texas, US) of the infusion line and irrigated continuously during the surgery. Vancomycin solution was prepared in the operation theatre by dissolving $1 \mathrm{~g}$ of Vancomycin in $10 \mathrm{ml}$ of sterile normal $(0.9 \%)$ sialine and then dissolving $1 \mathrm{ml}$ of this mixture in a sterile bottle of $500 \mathrm{ml}$ of infusion fluid. The cost of one cruet containing $1 \mathrm{~g}$ of Vancomycin is about 2 euro. This cruet is bought by the hospital pharmacy in advance.

If aspirate was to be cultured, the material suctioned with the use of the instrument was collected in a sterile bottle. A positive culture was interpreted as either growth of the identical organism on two or more media or confluent growth on one medium at the inoculation

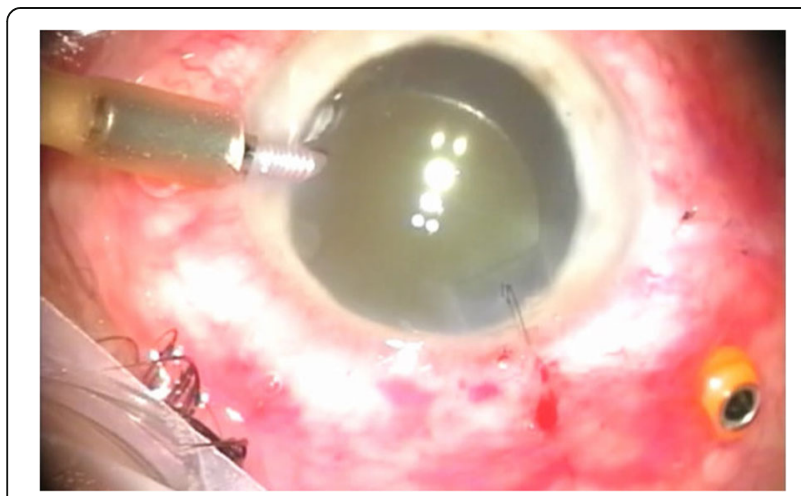

Fig. 2 Securing anterior chamber maintainer

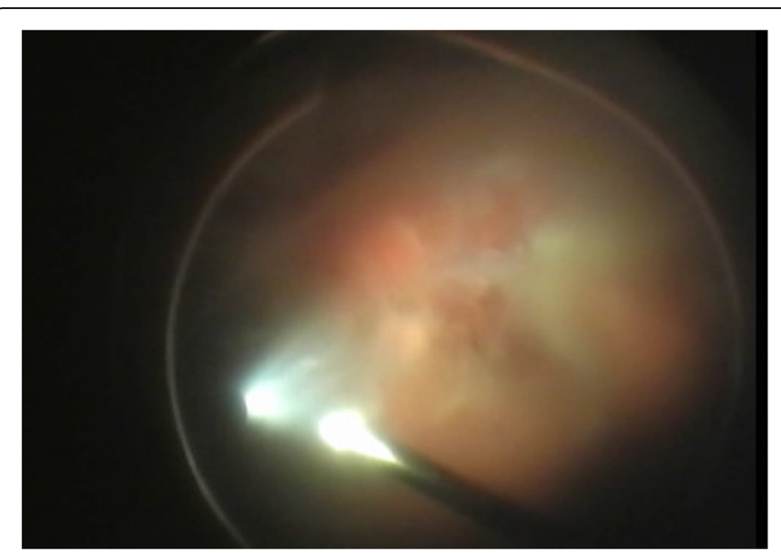

Fig. 3 Posterior vitreous detachment during vitrectomy

site [10]. All patients received topical (moxifloxacinevery $1 \mathrm{~h}$ ) and intravenous (cephazolin-2 x $1 \mathrm{~g}$ per day) broad-spectrum antibiotics to cover both Gram-positive and Gram-negative bacteria. This treatment was empirical and administered before the culture result was known.

\section{Results}

Study criteria were met by 45 patients: 30 with postoperative endophthalmitis and 15 with posttraumatic endophthalmitis (Tables 1 and 2). Median preoperative visual acuity in group with postoperative endophthalmitis was 3.0 $\log$ MAR, post PPV - $1.0 \operatorname{logMAR}(p=0.0001)$. Median preoperative visual acuity in group with posttraumatic endophthalmitis was $3.0 \operatorname{logMAR}$, post PPV - $1.3 \operatorname{logMAR}$ $(p=0.0001)$. There were no sinificant differences between final visual acuities between groups $(p<0.05)$.

Overall, after PPV the visual acuities were improved in 38 cases $(84 \%)-12$ posttraumatic and 26 postoperative, stable in seven cases (16\%) cases - 3 posttraumatic and four postoperative.

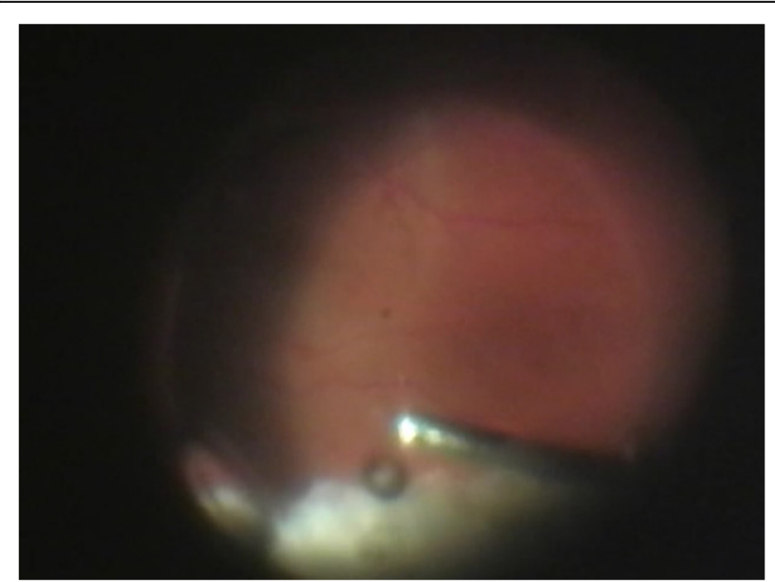

Fig. 4 Shaving peripheral vitreous during vitrectomy 
Table 1 Patient data, previous surgical procedures, surgical procedure in the treatment of endophthalmitis and results of visual acuity and result of microbiological culture regarding group of 30 patients with postoperative endophthalmitis

\begin{tabular}{|c|c|c|c|c|c|c|}
\hline No & $\begin{array}{l}\text { Gender, } \\
\text { age (years) }\end{array}$ & Previous surgical procedure & $\begin{array}{l}\text { Surgical procedure, } \\
\text { tamponade }\end{array}$ & $\begin{array}{l}\text { Initial visual } \\
\text { acuity } \\
\text { logMAR }\end{array}$ & $\begin{array}{l}\text { Final visual } \\
\text { acuity } \\
\text { logMAR }\end{array}$ & $\begin{array}{l}\text { Result of } \\
\text { microbiological } \\
\text { culture }\end{array}$ \\
\hline 1 & $\begin{array}{l}\text { Male, } \\
\text { age 50-55 }\end{array}$ & Phaco + IOL, trabeculectomy & $P P V+B S S$ & 3.0 & 2.0 & Culture negative \\
\hline 2 & $\begin{array}{l}\text { Male, } \\
\text { age } 70-75\end{array}$ & $\begin{array}{l}\text { Extracapsular cataract } \\
\text { extraction, aphakia }\end{array}$ & PPV + silicone oil & 3.0 & 2.0 & Culture negativee \\
\hline 3 & Male, age $80-85$ & Phaco + IOL, & PPV + silicone oil & 3.0 & 1.0 & Culture negative \\
\hline 4 & Female, age 70-75 & Phaco + IOL & PPV + silicone oil & 3.0 & 3.0 & Enterococcus fecalis \\
\hline 5 & Female, age $80-85$ & Phaco $+I O L$ & $\mathrm{PPV}+\mathrm{BSS}$ & 3.0 & 2.0 & Culture negative \\
\hline 6 & Male age $70-75$ & Avastin injection & $\begin{array}{l}\text { Phaco }+ \text { IOL+ } \\
\text { PPV }+ \text { BSS }\end{array}$ & 1.3 & 1.3 & $\begin{array}{l}\text { Staphylococcus } \\
\text { epidermidis }\end{array}$ \\
\hline 7 & Male, age $55-60$ & Secondary IOL implantation & $P P V+B S S$ & 3.0 & 0.4 & $\begin{array}{l}\text { Staphylococcus } \\
\text { epidermidis }\end{array}$ \\
\hline 8 & Male, age $70-75$ & Phaco + IOL & $P P V+B S S$ & 3.0 & 1.0 & Culture negative \\
\hline 9 & Female, age $80-85$ & Phaco + IOL & $P P V+B S S$ & 3.0 & 1.0 & $\begin{array}{l}\text { Staphylococcus } \\
\text { aureus }\end{array}$ \\
\hline 10 & Female, age 70-75 & Secondary IOL implantation & $P P V+B S S$ & 3.0 & 0.7 & Culture negative \\
\hline 11 & Male, age $50-55$ & Phaco + IOL + PPV + silicone oil & PPV + silicone oil removal + BSS & 1.3 & 1.0 & $\begin{array}{l}\text { Staphylococcus } \\
\text { epidermidis }\end{array}$ \\
\hline 12 & Female, age $65-70$ & $\begin{array}{l}\text { Ahmed valve implantation, } \\
\text { Phaco }+ \text { IOL }\end{array}$ & $\begin{array}{l}\mathrm{PPV}+\mathrm{KPL}+\mathrm{TKP}+\mathrm{IOL} \\
\text { explantation + silicone oil }\end{array}$ & 3.0 & 3.0 & Culture negative \\
\hline 13 & Female, age 60-65 & Phaco + IOL & $P P V+B S S$ & 3.0 & 1.0 & Culture negative \\
\hline 14 & Female, age 65-70 & Phaco + IOL & PPV + silicone oil & 3.0 & 1.0 & $\begin{array}{l}\text { Staphylococcus } \\
\text { aureus }\end{array}$ \\
\hline 15 & Female, age $80-85$ & Phaco + IOL & PPV + silicone oil & 3.0 & 1.3 & $\begin{array}{l}\text { Staphylococcus } \\
\text { aureus }\end{array}$ \\
\hline 16 & Male, age $75-80$ & Avastin intravitreal injection & $\begin{array}{l}\text { Paco }+I O L \\
+ \text { BSS }\end{array}$ & 3.0 & 1.0 & Culture negative \\
\hline 17 & Male, age $80-85$ & Phaco + IOL & $P P V+B S S$ & 3.0 & 0.4 & Culture negative \\
\hline 18 & Male, age 70-75 & Phaco + IOL & $P P V+B S S$ & 3.0 & 0.7 & $\begin{array}{l}\text { Staphylococcus } \\
\text { epidermidis }\end{array}$ \\
\hline 19 & Male, age 65-70 & Avastin intravitreal injection & $\begin{array}{l}\text { PPV + phaco } \\
+ \text { IOL + silicone oil }\end{array}$ & 3.0 & 1.3 & $\begin{array}{l}\text { Staphylococcus } \\
\text { epidemidis }\end{array}$ \\
\hline 20 & Female, age $70-75$ & Phaco + IOL & PPV + silicone oil & 0.7 & 0.5 & Culture negative \\
\hline 21 & Male, age $20-25$ & Phaco + IOL & PPV + silicone oil & 2.4 & 0.4 & Culture negative \\
\hline 22 & Male, age $50-55$ & Phaco + IOL & PPV + silicone oil & 3.0 & 1.0 & $\begin{array}{l}\text { Staphylococcus } \\
\text { epidermidis }\end{array}$ \\
\hline 23 & Female, age 70-75 & Secondary IOL implantation & $P P V+B S S$ & 2.4 & 2.0 & $\begin{array}{l}\text { Culture } \\
\text { negative }\end{array}$ \\
\hline 24 & Female, age 60-65 & Phaco + IOL & PPV + silicone oil & 2.4 & 1.0 & $\begin{array}{l}\text { Culture } \\
\text { negative }\end{array}$ \\
\hline 25 & Female, age $70-73$ & Phaco + IOL & PPV + silicone oil & 2.4 & 2.4 & $\begin{array}{l}\text { Enterococcus } \\
\text { fecalis }\end{array}$ \\
\hline 26 & Male, age $70-75$ & Phaco + IOL & $\mathrm{PPV}+\mathrm{BSS}$ & 2.4 & 0.7 & Culture negative \\
\hline 27 & Female, age 80-85 & Phaco+IOL & $P P V+B S S$ & 3.0 & 3.0 & $\begin{array}{l}\text { Streptococcus } \\
\text { oralis }\end{array}$ \\
\hline 28 & Female, age $80-85$ & Phaco + IOL & PPV + silicone oil & 2.4 & 1.7 & Culture negative \\
\hline 29 & Female, age 55-60 & Phaco + IOL & PPV + silicone oil & 2.1 & 2.4 & Bacillus cereus \\
\hline 30 & Female, age 60-65 & Phaco + IOL & TPPV + BSS & 2.1 & 0.7 & Culture negative \\
\hline
\end{tabular}

Abbreviations: Phaco phacoemulsification, PPV pars plana vitrectomy, BSS balanced salt solution, IOL intraocular lens, KPL keratoplasty, TKP temporary keratoprosthesis 
Table 2 Patient data, type of injury, surgical procedure and results of visual acuity and result of microbiological culture examination regarding group of 15 patients with posttraumatic endophthalmitis

\begin{tabular}{|c|c|c|c|c|c|c|}
\hline No & Gender, age & Type of injury, zone & $\begin{array}{l}\text { Surgical procedure, } \\
\text { tamponade }\end{array}$ & $\begin{array}{l}\text { Initial visual } \\
\text { acuity } \\
\text { logMAR }\end{array}$ & $\begin{array}{l}\text { Final visual } \\
\text { acuity } \\
\text { logMAR }\end{array}$ & $\begin{array}{l}\text { Result of } \\
\text { microbiological } \\
\text { culture }\end{array}$ \\
\hline 1 & Female, age $75-80$ & Pseudophakic, zone I & $P P V+B S S$ & 2.0 & 0.3 & Staphylococcus aureus \\
\hline 2 & Male, age $45-50$ & IOFB, traumatic cataract, zone I & $\mathrm{PPV}+$ phaco $+\mathrm{IOL}+$ silicone oil & 3.0 & 2.4 & Culture negative \\
\hline 3 & Male, age $25-30$ & IOFB, traumatic cataract zone I & PPV + phaco + IOL + silicone oil & 3.0 & 2.0 & Culture negative \\
\hline 4 & Male, age $55-60$ & Pseudophakic, zone III & $P P V+B S S$ & 3.0 & 0.4 & Staphylococcus aureus \\
\hline 5 & Male, age $45-50$ & Pseudophakic, zone I & $P P V+B S S$ & 2.0 & 1.3 & Culture negative \\
\hline 6 & Male, age 55-60 & Traumatic cataract, zone III & PPV + phaco + IOL+ silicone oil & 3.0 & 1.3 & Culture negative \\
\hline 7 & Female, age $35-40$ & Traumatic cataract, zone I & $\begin{array}{l}\text { Phaco + IOL + KPL } \\
+ \text { PPV + silicone oil }\end{array}$ & 3.0 & 3.0 & Bacillus cereus \\
\hline 8 & Male, age $40-45$ & IOFB, traumatic cataract, zone I & PPV+ phaco + IOL+ silicone oil & 2.0 & 2.0 & Culture negative \\
\hline 9 & Male, age $20-25$ & $\begin{array}{l}\text { Traumatic cataract, retinal detachment, } \\
\text { vitrous haemorrhage, IOFB, zone ॥ }\end{array}$ & PPV+ phaco + IOL+ silicone oil & 3.0 & 3.0 & Bacillus cereus \\
\hline 10 & Male, age $30-35$ & Traumatic cataract, zone III & PPV + phaco + IOL++silicone oil & 3.0 & 0.7 & Culture negative \\
\hline 11 & Male, age 60-65 & Traumatic cataract, IOFB, zone ॥ & PPV + phaco + IOL + silicone oil & 3.0 & 2.0 & Staphylococcus aureus \\
\hline 12 & Male, age $55-60$ & $\begin{array}{l}\text { Traumatic cataract, retinal } \\
\text { detachment, IOFB, zone II }\end{array}$ & PPV+ phaco + IOL+ silicone oil & 3.0 & 2.0 & $\begin{array}{l}\text { Staphylococcus } \\
\text { epidermidis }\end{array}$ \\
\hline 13 & Male, age $30-40$ & IOFB, traumatic cataract & $\mathrm{PPV}+$ phaco $+\mathrm{IOL}+\mathrm{BSS}$ & 3.0 & 0.5 & Culture negative \\
\hline 14 & Male, age $20-30$ & Traumatic cataract, zone I & PPV+ phaco + IOL silicone oil & 3.0 & 1.0 & $\begin{array}{l}\text { Staphylococcus } \\
\text { epidermidis }\end{array}$ \\
\hline 15 & Male, age $30-40$ & IOFB, traumatic cataract & PPV+ phaco + IOL SF6 gas & 3.0 & 0.5 & Culture negative \\
\hline
\end{tabular}

Abbreviations: Phaco phacoemulsification, PPV pars plana vitrectomy, BSS balanced salt solution, IOL intraocular lens, IOFB intraocular foreign body, TKP temporary keratoprosthesis

Mean intraocular pressure was $14 \mathrm{mmHg}$ (range $7-$ $18 \mathrm{mmHg}$ ) before treatment and $19 \mathrm{mmHg}$ (range 15$24 \mathrm{mmHg}$ ) after follow-up period.

In 12 cases PPV was combined with traumatic cataract removal with IOL implantation. Eyes after Avastin injections were phakic and PPV was combined with phacoemulsification and IOL implantation, in one case PPV was combined with IOL explantation. Retinal detachment was present in two cases of posttraumatic eyes, IOFB was present in eight cases. The mean time from the injury to wound repair was 2 days (1-4 days).

As a tamponade, BBS (20 cases - 4 posttraumatic and 16 postoperative) or 5000 sct silicone oil ( 25 cases-10 posttraumatic and 19 postoperative) or SF6 gas (one posttraumatic case) was used. PPV was combined with temporary keratoprosthesis (TKP) and keratoplasty in two patients (one posttraumatic and one postoperative).

Positive culture from either anterior chamber paracentesis or vitreous tapping or both were found in seven cases of posttraumatic eyes (47\%) of 15 patients (5 - Staphylococcus epidermidis; 2 - Bacillus cereus) and in 13 (43\%) cases of postoperative endophthalmitis (6 - Staphylococcus epidermidis, 3 - Staphylococcus aureus, 2 - Enterococcus fecalis, 1 - Bacillus cereus 1 - Streptococcus oralis). In 17 postoperative and eight posttraumatic cases culture was negative.
In the follow-up period of 1 year no retinal detachment was observed. Silicone oil was removed after mean period of 1 year and all retinas were attached. One from the operated cases, which underwent PPV combined with TKP and penetrating keratoplasty due to postoperative endophthalmitis following Ahmed valve implantation, ended in the phthisis bulbi. No eye was enucleated, no eye revealed signs of sympathetic ophthalmia.

\section{Discussion}

In the present study we retrospectively evaluated data of patients with endophthalmitis following intraocular surgery and open globe eye trauma treated with immediate $23 \mathrm{G}$ PPV with Vancomycin dissolved in the infusion fluid.

The Endophthalmitis Vitrectomy Study (EVS) - the major randomized trial in this subject - published in 1995 recommended intravitreal antibiotics if the visual acuity is greater than hand motion and PPV if visual acuity is equal to light perception [11]. EVS was designed to compare vitreous tapping with vitrectomy only in the treatment of postoperative endophthalmitis following cataract surgery and secondary IOL implantation. In this study there was no difference between final visual acuities with and without the use of systemic antibiotics. In EVS study $100 \%$ of Gram-postive bacteria were susceptible to Vancomycin.EVS study showed that 
immediate (defined by EVS as within $6 \mathrm{~h}$ from the presentation) PPV has satisfactory results and quicker recovery of vision in the management of this severe ocular infection only in eyes presented with light perception. However, many of the patients treated with vitreous tapping in fact underwent a mechanical vitrectomy, which is also called a vitreous biopsy. In effect, many of these patients underwent a vitrectomy, but it was a subtotal procedure (about $50 \%$ of the vitreous) without induction of posterior vitreous detachment.

In our study all the patients underwent a "complete" PPV with Vancomycin dissolved in the infusion fluid and there was significant improvement of the visual acuity both in postoperative and posttraumatic endophthalmitis. As it was advocated by Kuhn and co-workers, withdrawal of the vitreous body during PPV removes the bulk of infectious organisms and associated inflammatory debris load in the vitreous cavity and provides a large quantity of specimen for diagnostic smear and culture, and enables better antibiotics distribution [12]. Moreover, PPV reduces the incidence and severity of retinal, especially macular, complications and thus achieves a higher possibility of favorable visual outcome. Early PPV seems to be much more preferred in posttraumatic endophthalmitis, as more profound inflammation is observed and there is increased probability of more virulent organisms.

The surgical technique of PPV in endophthalmitis is similar to a standard PPV with some exceptions. Securing the infusion cannula correctly may be difficult due to purulent vitreous body and hazy cornea. A longer infusion cannula $(6 \mathrm{~mm})$ or anterior chamber maintainer may be useful. If here is oedema of the corneal epithelium, its scraping may be necessary to obtain good visibility of the retina and vitreous. In most of the cases removal of the hypopyon and fibrous membranes form the anterior chamber using 23G forceps is necessary. Peripheral shaving should be performed with care to avid iatrogenic breaks of the retina, as adherent vitreous and fragile retina may be more prone to developing retinal breaks and detachments. Posterior vitreous detachment was induced in all cases. Many surgeons give Vancomycin intravitreally at the end of the surgery, however, in our opinion, applying Vancomycin instantly during PPV in the infusion line gives the highest concentration "at the target site" and seems to be better for the circulation of the antibiotic in the eye during surgery (about $1 \mathrm{~h}$ ). Intravitreal administration of Vancomycin lasts for the limited time period only, there is a risk of iatrogenic damage - cataract and retinal breaks. Moreover, the margin for error between chemotherapy and retinal toxicity is very narrow.

Vancomycin is effective against most Gram-positive bacteria, also methycillin-resistant, including Staphylococcus,
Streptococcus and Bacillus species. Vancomycin is a glycopeptide antibiotic inhibiting bacterial cell wall protein synthesis by binding to the 30S rRNA molecule of the bacterial ribosome. Resistant mutants are very rare. Vancomycin seems to be well tolerated by ocular structures, it is cleared from the eye anteriorly, resulting in a long half-life. There is also no evidence of retinal toxicity. Data from rabbit studies demonstrated a vitreal half-life of 20-40 $\mathrm{h}$ in uninfected rabbit eyes and 38-54 $\mathrm{h}$ in infected rabbit eyes [13].

It has been shown that intravenous Vancomycin does not reach therapeutic concentrations in vitreous due to the protective effect of the blood-ocular fluid barrier [14]. However, intraocular inflammation increases the permeability of the blood-ocular fluid barrier, enhancing penetration of systemic antibiotics into the vitreous cavity [14].

There are no strict indications for intravitreal Vancomycin injection as the primary treatment. It depends on the individual decision made by the surgeon. In our opinion it should be reserved for endophthalmitis cases with visible red reflex and visual acuity better than 0.1 .

In a rabbit model of endophthalmitis caused by intravitreal injection of Bacillus cereus, it has been demonstrated that eyes treated with combined PPV and intraocular Vancomycin during the early stage of infection resulted in significantly greater retinal function compared with that of intraocular antibiotics alone [15].

There are reports that Vancomycin in some countries, especially in Europe, is used intracamerally or in the irrigating solution during cataract surgery as a prophylaxis of endophthalmitis [16, 17]. However, it may increase the risk of Vancomycin-resistant bacteria growth, thus Vancomycin should not be used for prohylaxis of endophthalmitis.

Direct intracameral injection of cefuroxime $(1 \mathrm{mg})$ given at the end of the surgery is recommended by the ESCRS guidelines as a standard prophylactic intervention significantly reducing the postoperative infections rate [2]. In our hospital we use intracameral cefuroxime routinely in all patients at the end of cataract surgery, without exceptions, but we are not confident if it is the same in all regional hospitals in Poland. In a recent national Survey in Europe it was investigated the role of intracameral cefuroxime in the prevention of endophthalmitis following cataract surgery [18]. An incidence of endophthalmitis greater than $0.13 \%$ was encountered significantly more frequently among centers that did not employ intracameral cefuroxime. However, we need to have updated data and try to choose the antibiotics based on the local microbiological surveillance [18]. Preoperative application of povidone - iodine to skin and conjunctiva seems to be proven intraoperative endophthalmitis prophylaxis [19]. This is the best surgical preparation technique. The systemic antibiotics decrease the bacteria loading to the eye in 
endophthalmitis. In our group of patients we used intravenous cephazolin - a first generation cephalosporin antibiotic. Topical antibiotic used in this study was fluorochinolon moxifloxacin. It has been shown that fuorchinolones penetrate into the inflamed and non-inflammed vitreous better than other classes of antibiotics [20]. However, in the light of "choosing wisely" philosophy we should not probably use fluorquinolones preoperatively, but we also think that in the real world medical legal issues may predominate in our decisions [21]. Large studies have shown that there are several changes in bacteria composition of the conjunctiva over time [22-24]. Moreover, our concerns are about the increased resistance of Gram + germs to fluorquinolones. From the other side, it was proven that postoperative usage of fluorquinolones reduces the risk of endophthalmtis [25].

It is difficult to compare our results with other studies, as there is no standardized approach to the management of posttraumatic endophthalmitis. Microincision vitrectomy surgery, including 23- and 25-gauge PPV, is often described as being minimally invasive.

In our study most of the cases were treated with $23 \mathrm{G}$ PPV and silicone oil as a tamponade, as it does not support microbial growth [26]. Moreover, in an in vitro study, silicone oil was effective in the suppression of multiple endophthalmitis causing organisms [27]. The technological advances of small-gauge PPV seem to afford visual benefit, with more rapid healing, less discomfort, and an acceptably low incidence of adverse events compared with those observed in conventional 20-gauge PPV [28]. A discussion still exists concerning the appropriate timing for PPV in traumatized eyes. However, most reports agree that PPV should be performed without delay in severe cases of endophthalmitis, especially those involving IOFB [6].

In the present study there were no significant differences in final visual acuity between eyes with postoperative and posttraumatic endophthalmitis. However, it has already been shown, that there are different factors responsible for worse than postoperative endophthalmitis visual prognosis: virulence of the infectious organism, the severity of associated trauma, the rapidity of diagnosis and institution of therapy [29], as well as poor presenting visual acuity, inability to visualize the optic disc on indirect ophthalmoscopy, presence of vitreous membranes on ultrasonography, trauma by a needle and a culture-positive vitreous biopsy [3].

In our study the positive cultures were found in $44 \%$ of cases. In the literature the rate of positive cultures is similar: $40 \%$ in study of 97 patients by Vedantham [30], 44 \% in the study of 955 samples analyzed by Ramakrishnan and co-operators [31] and $58 \%$ in the study of 62 patients conducted by Das [32].

There has been wide variety of pathogens found in the studies dealing with posttraumatic and postoperative endophthalmitis [32]. Coagulase-negative Staphylococcus remains the most frequently identified cause of endophthalmitis [33]. Bacillus cereus is ranked second behind Staphylococci in the prevalence of posttraumatic endophthalmitis and some cases are polymicrobal. In our study Staphylococcus epidermidis, Bacillus cereus, Enterococcus fecalis and Streptococcus oralis were found in microbiological examination in half of cases. The low rate of culture positivity in this study could be due to poor sampling technique, the use of antibiotics postoperatively or simply sterile endophthalmitis. It has been already reported that cases with negative cultures at presentation were more likely to have improvement in visual acuity compared with culture-positive cases [34]. Ramakrishnan and colleagues [31] reported in 10-years retrospective study that the intraocular specimen may remain culture-negative despite obvious signs of infection in certain cases of posttraumatic endophthalmitis.

In the setting of an IOFB or soil contamination there is a high incidence of Bacillus species endophthalmitis [6]. Endophthalmitis caused by Bacillus cereus is characterized by a rapid onset of severe pain, inflammation and progression to panophthalmitis. The current antibiotic treatment for acute-onset bacterial endophthalmitis includes Vancomycin for gram-positive coverage and either ceftazidime or an aminoglycoside for gramnegative coverage [35].

The incidence of posttraumatic endophthalmitis may be decreased by early wound closure and prompt initiation of antibiotics. Prophylactic factors in the setting of trauma include primary wound repair within $24 \mathrm{~h}$, lack of tissue prolapse into wounds and self-sealing wounds [36]. Systemic broad-spectrum antibiotic therapy is a common approach to prophylaxis against endophthalmitis in the setting of open-globe injury [37].

\section{Conclusions}

We believe that Vancomycin is still an excellent antibiotic for the empirical treatment of bacterial endophthalmitis. Antibiotic choice in preventing endophthalmitis after ophthalmic surgery should be based on knowing the organisms causing endophthalmitis in that region, along with their antibiotic susceptibilities. In every tertiary vitreoretinal center, clear treatment guidelines should be established, all necessary antibiotics and an examination of the microbiological specimens should be available at all times.

The results of this retrospective study support the use of early PPV combined with Vancomycin in infusion in cases of both postoperative and posttraumatic infectious endophthalmitis. With this strategy the final visual outcome may be markedly improved.

Funding

No funding was obtained for this study. 


\section{Availability of data and materials}

All the data are available upon request.

\section{Authors' contributions}

RR - substantial contribution to conception and design of the study, analysis and interpretation of data, drafting the manuscript, $\mathrm{KN}$ - analysis and interpretation of the data, drafting the manuscript, TC, AK - acquisition and substantial analysis of the data, MK, PK, JMW - drafting the manuscript and revising it critically for important intellectual content, AJ, RM - substantial contribution to analysis and interpretation of the data. All authors read and approved the final manuscript.

\section{Competing interests}

The authors declare that they have no competing interests.

\section{Consent for publication}

Written consent to publish the information contained in the manuscript and tables was obtained from all participants.

\section{Ethics approval and consent to participate}

The study was approved by the local Ethic Committee at the University in Lublin, Poland. The patients gave their written informed consent to participate in the study and publish the data.

\section{Author details}

'Department of General Ophthalmology, Medical University of Lublin, ul. Chmielna 1, 20-079 Lublin, Poland. ${ }^{2}$ Department of Experimental Pharmacology, Medical Research Centre, Polish Academy of Sciences, Warsaw, Poland. ${ }^{3}$ Department of Didactics and Medical Simulation, Human Anatomy Chair, Medical University of Lublin, Lublin, Poland. ${ }^{4}$ Department of Ophthalmology, University of Heidelberg, Heidelberg, Germany. ${ }^{5}$ Department of Public Health, Medical University of Lublin, Lublin, Poland. ${ }^{6}$ Human Anatomy Department, Medical University of Lublin, Lublin, Poland.

7Department of Ophthalmology, University of Rostock, Rostock, Germany.

Received: 16 February 2016 Accepted: 10 September 2016

Published online: 20 September 2016

\section{References}

1. Callegan MC, Engelbert M, Parke 2nd DW, et al. Bacterial endophthalmitis: epidemiology, therapeutics, and bacterium-host interactions. Clin Microbiol Rev. 2002;15(1):111-24

2. ESCRS Guidelines on prevention, investigation and management of post-operative endophthalmitis. Editors Peter Barry, Wolfgang Behrens-Baumann, Uwe Pleyer \& David Seal. The European Society for Cataract \& Refractive Surgeons, Version 2 August 2007

3. Das T, Kunimoto DY, Sharma S, Jalali S, Majii AB, Nagaraja Rao T, Gopinathan U, Athmanathan S, Endophthalmitis Research Group. Relationship between clinical presentation and visual outcome in postoperative and posttraumatic endophthalmitis in south central India. Indian J Ophthalmol. 2000;48:123-8.

4. Essex RW, Yi Q, Charles PG, Allen PJ. Post-traumatic endophthalmitis. Ophthalmology. 2004;111(11):2015-22.

5. Boldt HC, Pulido JS, Blodi CF, Folk JC, Weingeist TA. Rural endophthalmitis. Ophthalmology. 1989;96(12):1722-6.

6. Thompson JT, Parver LM, Enger CL, Mieler WF, Liggett PE. Infectious endophthalmitis after penetrating injuries with retained intraocular foreign bodies. Ophthalmology. 1993;100(10):1468-1474.7.

7. Al-Mezaine HS, Osman EA, Kangave D. Risk factors for culture-positive endophthalmitis after repair of open globe injuries. Eur J Ophthalmol. 2010;20(1):201-8.

8. Kresloff MS, Castellarin AA, Zarbin MA. Endophthalmitis. Surv Ophthalmol. 1998:43(3):193-224.

9. Kuhn F, Morris R, Witherspoon CD, Heimann K, Jeffers JB, Treister G. A standardized classification of ocular trauma. Ophthalmology. 1996;103:240-3.

10. Maguire Jl. Postoperative endophthalmitis: optimal management and the role and timing of vitrectomy surgery. Eye. 2008;22(10):1290-300.

11. Endophthalmitis Vitrectomy Study Group. Results of the Endophthalmitis Vitrectomy Study. A randomized trial of immediate vitrectomy and of intravenous antibiotics for the treatment of postoperative bacterial endophthalmitis. Arch Ophthalmol 1995; 113(12): 1479-1496.
12. Kuhn F, Gini G. Ten years after... are findings of the endophthalmitis vitrectomy study still relevant today? Graefes Arch Clin Exp Ophthalmol. 2005;243:1197-9.

13. Smith MA, Sorensen JA, Lowy FD, et al. Treatment of experimental methicillin resistant staphylococcus epidermidis endophthalmitis with intravitreal vancomycin. Ophthalmology. 1986;93:1328-35.

14. Ferencz JR, Assia El, Diamantstein L, Rubinstein E. Vancomycin concentration in the vitreous after intravenous and intravitreal administration for postoperative endophthalmitis. Arch Ophthalmol. 1999;117(8):1023-7.

15. Callegan MC, Guess S, Wheatley NR, Woods DC, Griffin G, Wiskur BJ, Leonard R. Efficacy of vitrectomy in improving the outcome of Bacillus cereus endophthalmitis. Retina. 2011:31(8):1518-1524.15.

16. Anijeet DR, Palimar P, Peckar CO. Intracameral vancomycin following cataract surgery: an eleven-year study. Clin Ophthalmol. 2010;26:321-6.

17. Sobaci G, Tuncer $K$, Taş A, Ozyurt M, Bayer A, Kutlu U. The effect of intraoperative antibiotics in irrigating solutions on aqueous humor contamination and endophthalmitis after phacoemulsification surgery. Eur J Ophthalmol. 2003:13:773-8.

18. Grosso A, Pertile G, Marchini G, Scarpa G, Ceruti P, Prigione G, Romano MR, Bert F, Gili R, Panico C, Siliquini R, Engelbert M. Adherence to European society for cataract and refractive surgery recommendations among Italian cataract surgeons: a survey. Eur J Ophthalmol. 2016;8.

19. Apt L, Isenberg S, Yorhimori R. Chemical preparation of the eye in ophthalmic surgery: the effect of povidone-iodine on the conjunctiva. Arch Ophthalmol. 1984;102:728-9.

20. Fiscella RG, Nguyen TK, Cwik MJ, et al. Aqueous and vitreous penetration of levofloxacin after oral administration. Ophthalmology. 1999;106:2286-90.

21. Parke 2nd DW, Coleman AL, Rich 3rd WL, et al. Choosing wisely: five ideas that physicians and patients can discuss. Ophthalmology. 2013; 120:443-4.

22. Hsu J, Gerstenblith AT, Garg SJ, et al. Conjunctival flora antibiotic resistance patterns after serial intravitreal injections without postinjection topical antibiotics. Am J Ophthalmol. 2014:157:3514-518.

23. Dave SB, Toma HS, Kim SJ. Changes in ocular flora in eyes exposed to ophthalmic antibiotics. Ophthalmology. 2013;120:937-41.

24. Gower EW1, Lindsley K, Nanji AA, et al. Perioperative antibiotics for prevention of acute endophthalmitis after cataract surgery. Cochrane Database Syst Rev. 2013;7:CD006364.

25. Rudnisky CJ, Wan D, Weis E. Antibiotic choice for the prophylaxis of post-cataract extraction endophthalmitis. Ophthalmology. 2014;121:835-41.

26. Azad R, Ravi K, Talwar D, Rajpal Kumar N. Pars plana vitrectomy with or without silicone oil endotamponade in post-traumatic endophthalmitis. Graefes Arch Clin Exp Ophthalmol. 2003;241(6):478-83.

27. Ozdamar A, Aras C, Ozturk R, Akin E, Karacorlu M, Ercikan C. In vitro antimicrobial activity of silicone oil against endophthalmitis-causing agents. Retina. 1999;19(2):122-126.20

28. Recchia FM, Scott IU, Brown GC, Brown MM, Ho AC, Ip MS. Small-gauge pars Plana vitrectomy: a report by the American academy of ophthalmology. Ophthalmology. 2010;117(9):1851-7.

29. Brinton GS, Topping TM, Hyndiuk RA, Aaberg TM, Reeser FH, Abrams GW. Posttraumatic endophthalmitis. Arch Ophthalmol. 1984:102(4):547-50.22.

30. Vedantham V, Nirmalan PK, Ramasamy K, Prakash K, Namperumalsamy P. Clinico-microbiological profile and visual outcomes of post-traumatic endophthalmitis at a tertiary eye care center in South India. Indian J Ophthalmol. 2006:54(1):5-10.

31. Ramakrishnan R, Bharathi MJ, Shivkumar C, Mittal S, Meenakshi R, Khadeer $M A$, Avasthi A. Microbiological profile of culture-proven cases of exogenous and endogenous endophthalmitis: a 10-year retrospective study. Eye. 2009;23:945-56

32. Das T, Hussain A, Naduvilath T, Sharma $\mathrm{S}$, Jalali S, Majii AB. Case control analyses of acute endophthalmitis after cataract surgery in South India associated with technique, patient care, and socioeconomic status. J Ophthalmol. 2012;2012:298459.

33. Gentile RC, Shukla S, Shah M, et al. Microbiological spectrum and antibiotic sensitivity in endophthalmitis: a 25-year review. Ophthalmology. 2014;121:1634-42.

34. Nobe JR, Gomez DS, Liggett P, Smith RE, Robin JB. Post-traumatic and postoperative endophthalmitis: a comparison of visual outcomes. $\mathrm{Br}$ Ophthalmol. 1987;71(8):614-7. 
35. Roth DB, Flynn HW. Antibiotic selection in the treatment of endophthalmitis: the significance of drug combinations and synergy. Surv Ophthalmol. 1997;41:395-40.

36. Ahmed Y, Schimel AM, Pathengay A, Colyer MH, Flynn HW. Endophthalmitis following openglobe injuries. Eye. 2012;26:212-7.

37. Bhagat N, Nagori S, Zarbin M. Post-traumatic infectious endophthalmitis. Surv Ophthalmol. 2011;56(3):214-5.

Submit your next manuscript to BioMed Central and we will help you at every step:

- We accept pre-submission inquiries

- Our selector tool helps you to find the most relevant journal

- We provide round the clock customer support

- Convenient online submission

- Thorough peer review

- Inclusion in PubMed and all major indexing services

- Maximum visibility for your research

Submit your manuscript at www.biomedcentral.com/submit 